05;06

\title{
Моделирование влияния агломерации графена на механические свойства керамических композитов с графеном
}

\author{
(C) А.Г. Шейнерман ${ }^{1}$, С.А. Красницкий 2,3 \\ ${ }^{1}$ Институт проблем машиноведения РАН, Санкт-Петербург, Россия \\ ${ }^{2}$ Санкт-Петербургский политехнический университет Петра Великого, Санкт-Петербург, Россия \\ ${ }^{3}$ Национальный исследовательский университет ИТМО, Санкт-Петербург, Россия \\ E-mail: asheinerman@gmail.com
}

Поступило в Редакцию 27 апреля 2021 г.

В окончательной редакции 19 мая 2021г.

Принято к публикации 27 мая 2021 г.

\begin{abstract}
Предложена модель, описывающая пористость, твердость и вязкость разрушения керамических композитов с агломератами графеновых пластинок. В модели предполагается, что агломерация пластин графена происходит в процессе горячего прессования таких композитов, а вокруг агломератов образуются поры. В рамках модели рассчитаны зависимости пористости, твердости и вязкости разрушения керамических композитов с графеном от объемной доли графена. Показано, что образование пор объясняет экспериментально наблюдаемое падение твердости и вязкости разрушения композитов при превышении объемной долей графена критического значения. Результаты модели согласуются с экспериментальными данными для композитов $\mathrm{Al}_{2} \mathrm{O}_{3}-\mathrm{WC}-\mathrm{TiC}$, усиленных пластинками графена.
\end{abstract}

Ключевые слова: керамики, композиты, графен, разрушение.

DOI: 10.21883/PJTF.2021.17.51385.18844

Известно, что добавки графена могут существенно повысить твердость и трещиностойкость керамик [1-4]. Вместе с тем повышение твердости и трещиностойкости керамик за счет добавления графена происходит лишь при малых концентрациях графеновых пластинок. Напротив, при высокой концентрации графена твердость и трещиностойкость керамик уменьшаются с ростом объемной доли графена [1-3,5-7]. При этом экспериментальные данные [1-3,5-7] указывают на резкое падение указанных характеристик вблизи некоторого критического значения концентрации графена. Резкое уменьшение твердости и вязкости разрушения керамических композитов с графеном может быть связано [1,3] с агломерацией пластин графена и формированием пор вокруг образованных агломератов. Целью настоящей работы является разработка модели, описывающей влияние агломерации графеновых пластин на пористость, твердость и вязкость керамических композитов с графеном.

В рамках модели предположим, что агломерация пластин графена происходит в процессе горячего прессования керамических композитов с графеном в результате скольжения графена по границам зерен при температурах прессования. Будем полагать, что агломерация пластинок графена в процессе горячего прессования происходит, если расстояние между центрами этих пластинок меньше некоторого критического значения. С учетом экспериментальных наблюдений пор возле агломератов пластинок графена [1,5-7] предположим также, что возле всех агломератов, состоящих из любого большего единицы числа пластинок графена, образуются поры. Для расчета зависимости величины пористости композита „керамика/графен“ от объемной доли графена будем считать, что расстояние $r$ между центром произвольной пластинки графена и центром ближайшей к ней другой графеновой пластинки подчиняется логнормальному распределению

$$
\rho(r)=\frac{1}{r \sqrt{2 \pi s^{2}}} \exp \left(-\frac{\left(\ln (r / \bar{r})+s^{2} / 2\right)^{2}}{2 s^{2}}\right),
$$

где $\bar{r}-$ среднее значение $r$, а $s-$ среднеквадратичное отклонение величины $\ln r$. Обозначая объемную долю графена в композите как $f_{v}$, а средний объем пластинки как $V_{p l}$, можно оценить среднее расстояние между ближайшими пластинками графена как $\bar{r}=\left(V_{p l} / f_{v}\right)^{1 / 3}$. Из последнего соотношения следует, что $r / \bar{r}=\kappa f_{v}^{1 / 3}$, где $\kappa=r / V_{p l}^{1 / 3}$.

Пусть агломерация пластинок графена происходит, если расстояние между их центрами меньше некоторого критического значения $r^{*}$, называемого в дальнейшем радиусом агломерации. Тогда доля пластинок, которые участвуют в агломерации, равна вероятности $P\left(r<r^{*}\right)$ того, что для случайной пластинки выполняется условие $r<r^{*}$. Будем полагать, что для заданного распределения $\rho(r)$ пластинки с меньшим значением $r$ (характеризующим расстояние от их центра до центра другой ближайшей пластинки) будут в среднем находиться на пропорционально меньших расстояниях от центров других соседних с ними пластинок. При этом предположении количество пластин в агломерате с участием пластинки, характеризующейся расстоянием $r$ до другой ближайшей пластинки (таким, что $r<r^{*}$ ), можно приближенно оценить как $\alpha r^{* 3} / r^{3}$, где $\alpha-$ множитель, зависящий 
от пространственного расположения пластинок. Тогда отношение количества пор возле агломератов пластинок графена к исходному количеству пластинок графена равно $\alpha \int_{0}^{r^{*}} \rho(r)\left(r / r^{*}\right)^{3} d r$. Предполагая, что объем поры возле произвольного агломерата пластинок графена не зависит от количества пластинок графена в агломерате и равен $V_{p}$, объемную долю $f_{p}$ пор после агломерации можно рассчитать по формуле

$$
f_{p}=\beta f_{v} \int_{0}^{r^{*}} \rho(r)\left(r / r^{*}\right)^{3} d r=\beta f_{v} \int_{0}^{\kappa^{*}} \rho_{1}(\kappa)\left(\kappa / \kappa^{*}\right)^{3} d \kappa,
$$

где $\beta=\alpha V_{p} / V_{p l}, \rho_{1}(\kappa)=\left[1 /\left(\kappa \sqrt{2 \pi s^{2}}\right)\right] \exp \left(-\left[\ln \left(\kappa f_{v}^{1 / 3}\right)+\right.\right.$ $\left.\left.+s^{2} / 2\right]^{2} /\left(2 s^{2}\right)\right)$, и $\kappa^{*}=r^{*} / V_{p l}^{1 / 3}$.

Формула (2) позволяет оценить величину пористости $f_{p}$ керамических композитов с графеном, связанной с агломерацией пластинок графена, и относительную (безразмерную) плотность таких композитов (определяемую как отношение реальной плотности композита к плотности аналогичного композита, не содержащего пор). Обозначая относительную плотность керамического композита с графеном при отсутствии пор, связанных с агломерацией пластинок графена, как $R_{0}$, относительную плотность $R$ аналогичного композита, содержащего поры, можно рассчитать с помощью соотношения $R=R_{0}-f_{p}$.

Зависимость относительной плотности $R$ керамического композита с графеном от объемной доли $f_{v}$ графена приведена на рис. 1 для следующих значений параметров: $\beta=2.9, \kappa^{*}=4.8, s=0.12$ и $R_{0}=0.9958$. Для сравнения на рис. 1 точками показаны экспериментальные значения [5] относительной плотности для композитов $\mathrm{Al}_{2} \mathrm{O}_{3}-\mathrm{WC}-\mathrm{TiC}$, усиленных пластинками графена (далее обозначаемых как $\mathrm{Al}_{2} \mathrm{O}_{3}-\mathrm{WC}-\mathrm{TiC}-G r$ ). Как видно из рис. 1 , расчетные значения относительной

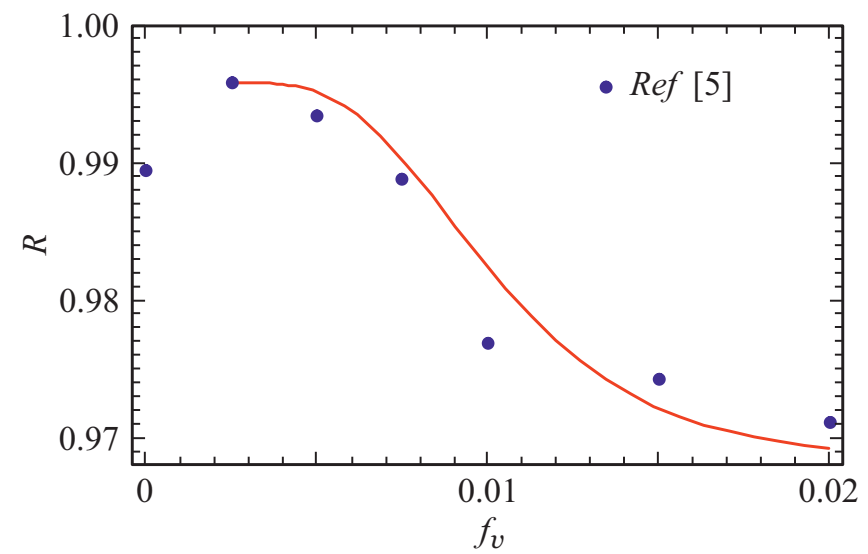

Рис. 1. Зависимости относительной плотности $R$ композита $\mathrm{Al}_{2} \mathrm{O}_{3}-\mathrm{WC}-\mathrm{TiC}-G r$ от объемной доли $f_{v}$ графена. Для сравнения точками показаны экспериментальные значения относительной плотности [5]. плотности хорошо согласуются с экспериментальными данными [5].

Оценим теперь влияние пор, образующихся в результате агломерации пластинок графена, на твердость керамических композитов с графеном. В отсутствие пор твердость по Виккерсу $H_{d}$ керамического композита с пластинками графена, ориентированными преимущественно в параллельных плоскостях, можно приближенно оценить по формуле

$$
H_{d}=H_{0}\left[1+\left(E_{g}-E_{m}\right) f_{v} / E_{m}\right]+k\left(d^{-1 / 2}-d_{0}^{-1 / 2}\right) .
$$

Здесь $H_{0}-$ твердость матрицы, $E_{m}-$ модуль Юнга матрицы, $E_{g}-$ упругий модуль пластинок графена в направлениях, параллельных его плоскостям, $d_{0}$ и $d-$ размеры зерен матрицы и композита с графеном соответственно, $k$ - константа Холла-Петча для твердости. Первое слагаемое в формуле (3) связано с переносом нагрузки на графеновые пластины [8], а второе - с изменением твердости при изменении размера зерна матрицы, связанном с наличием графена. При наличии пор вклад в перенос нагрузки на графеновые пластины вносят только пластинки, не подвергшиеся агломерации и соответственно не окруженные порами.

Кроме того, наличие пористости ведет к дополнительному уменьшению твердости материала. Для рассматриваемого случая малой пористости $\left(f_{p} \ll 1\right)$ твердость по Виккерсу композита с графеном можно оценить по формуле

$$
\begin{aligned}
H_{V} & =\left[H_{0}\left(1+\left(E_{g}-E_{m}\right) f_{v}\left[1-P\left(f_{v}\right)\right] / E_{m}\right)\right. \\
& \left.+k\left(d^{-1 / 2}-d_{0}^{-1 / 2}\right)\right]\left(1-a f_{p}\right) .
\end{aligned}
$$

Здесь $P\left(f_{v}\right)$ - доля пластинок, участвующих в агломерациях и соответственно не увеличивающих твердость материала; $a-$ безразмерный параметр, зависящий от формы пор [9].

С помощью формулы (4) мы рассчитали зависимость твердости по Виккерсу керамического композита с графеном от объемной доли графена для случая композитов $\mathrm{Al}_{2} \mathrm{O}_{3}-\mathrm{WC}-\mathrm{TiC}-G r$. Для этого мы в первом приближении использовали для композита значение модуля Юнга матрицы $E_{m}=409 \mathrm{GPa}$ [10], характерное для чистого $\mathrm{Al}_{2} \mathrm{O}_{3}$ (составляющего основу композита), и следующие значения остальных параметров: $E_{g}=1 \mathrm{TPa}$ [5], $a=8, H_{0}=25 \mathrm{GPa}$. Поскольку изменение размера зерна в образцах композитов $\mathrm{Al}_{2} \mathrm{O}_{3}-\mathrm{WC}-\mathrm{TiC}$ с различным содержанием графена было очень небольшим [5], мы также пренебрегли связанным с ним изменением твердости образцов. Для построения кривых мы также учли, что относительная плотность композита без добавок графена (равная 0.9894) была ниже, чем относительная плотность образцов с малым содержанием графена, т.е. малые концентрации графена, при которых не происходила агломерация пластинок графена, приводили к уменьшению пористости [5]. 


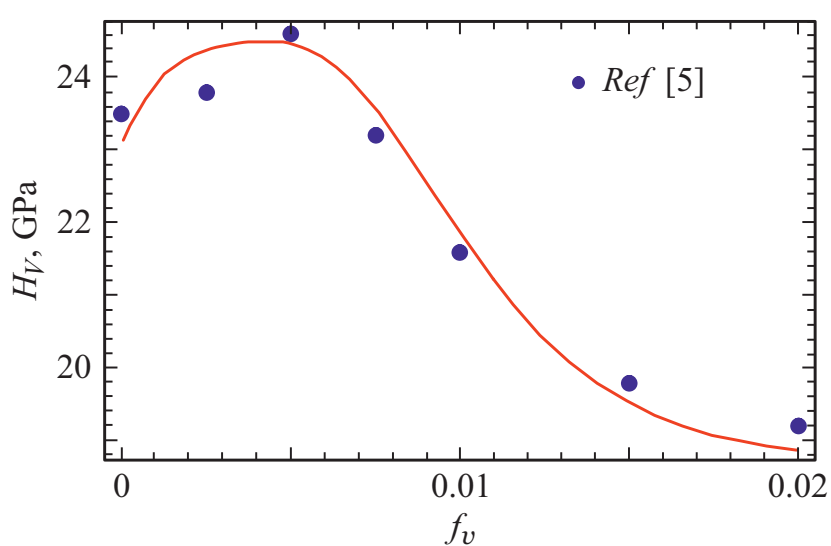

Рис. 2. Зависимости твердости по Виккерсу $H_{V}$ композита $\mathrm{Al}_{2} \mathrm{O}_{3}-\mathrm{WC}-\mathrm{TiC}-G r$ от объемной доли $f_{v}$ графена. Для сравнения точками показаны экспериментальные значения твердости [5].

Зависимости твердости по Виккерсу керамических композитов $\mathrm{Al}_{2} \mathrm{O}_{3}-\mathrm{WC}-\mathrm{TiC}-G r$ от объемной доли $f_{v}$ графена приведены на рис. 2. Точками на рис. 2 отмечены экспериментальные значения твердости [5]. Как видно из рис. 2, твердость образца сначала увеличивается, а затем уменьшается с ростом объемной доли графена. Увеличение твердости при малой концентрации графена связано в первую очередь с уменьшением пористости и лишь в небольшой степени с переносом нагрузки на графеновые пластинки. Уменьшение твердости с ростом объемной доли графена при $f_{v}>0.005$ связано с агломерацией пластинок графена и образованием возле них пор. Из рис. 2 видно, что расчетная кривая хорошо согласуется с экспериментальными значениями [5] твердости композитов $\mathrm{Al}_{2} \mathrm{O}_{3}-\mathrm{WC}-\mathrm{TiC}-G r$.

Рассчитаем теперь влияние пор, образующихся в результате агломерации пластинок графена, на вязкость разрушения керамических композитов с графеном. Для определенности будем полагать, что основной механизм увеличения вязкости разрушения, связанного с графеном, заключается в образовании мостиков между берегами трещин (бриджинге). В этом случае вязкость разрушения $K_{I C}^{d}$ в отсутствие пор описывается соотношением [11]:

$$
K_{I C}^{d}=K_{I C}^{0}+A f_{v}^{0.8},
$$

где $K_{I C}^{0}$ - вязкость разрушения матрицы, $A-$ параметр, зависящий от размеров графеновых пластин. При наличии пор вклад в увеличение вязкости разрушения вносят только пластинки, не подвергшиеся агломерации и соответственно не окруженные порами. Кроме того, наличие пористости ведет к дополнительному уменьшению вязкости разрушения материала. В первом приближении для оценки влияния пор на вязкость разрушения будем использовать результаты модели [12], описывающей вязкость разрушения материала с прямоугольным ансамблем цилиндрических пор. Используя результаты этой модели, мы можем представить вязкость разрушения $K_{I C}$ керамических композитов с графеном при наличии пор в виде

$$
K_{I C}=\left\{K_{I C}^{0}+A\left[f_{v}\left(1-P\left(f_{v}\right)\right)\right]^{0.8}\right\}\left(1-2 \sqrt{f_{p} / \pi}\right) .
$$

В формуле (5) множитель $1-P\left(f_{v}\right)$ определяет долю пластинок, не окруженных порами и вносящих вклад в увеличение вязкости разрушения в результате бриджинга, а множитель $1-2 \sqrt{f_{p} / \pi}$ определяет уменьшение вязкости разрушения, связанное с увеличением локальных напряжений в материале в результате образования пор.

Зависимости вязкости разрушения $K_{I C}$ керамического композита $\mathrm{Al}_{2} \mathrm{O}_{3}-\mathrm{WC}-\mathrm{TiC}-G r$ от объемной доли $f_{v}$ графена приведены на рис. 3 для значений параметров $K_{I C}^{0}=9.2 \mathrm{MPa} \cdot \mathrm{m}^{1 / 2}$ и $A=120 \mathrm{MPa} \cdot \mathrm{m}^{1 / 2}$. Точками на рис. 3 отмечены экспериментальные значения вязкости разрушения [5]. Как следует из рис. 3, вязкость разрушения композита сначала увеличивается, а затем уменьшается с ростом объемной доли графена. Увеличение вязкости разрушения при добавлении графена в интервале $f_{v}<0.005$ связано как с уменьшением пористости, так и с эффектом бриджинга. При $f_{v}>0.005$ в материале начинают образовываться поры возле графеновых пластин, и эффект бриджинга постепенно пропадает, а отрицательное влияние пор на вязкость разрушения усиливается. Как видно из рис. 3, расчетная кривая удовлетворительно согласуется с экспериментальными значениями [5] вязкости разрушения керамического композита $\mathrm{Al}_{2} \mathrm{O}_{3}-\mathrm{WC}-\mathrm{TiC}-G r$.

Таким образом, предложенная модель объясняет наблюдаемое (см., например, [1-3,5-7]) падение твердости и вязкости разрушения керамических композитов с графеном при превышении объемной долей графена критического значения. Показано, что ухудшение этих механических характеристик керамических композитов с графеном связано с образованием пор вокруг агломератов графеновых пластин, а критическое значение объемной доли графена зависит от радиуса

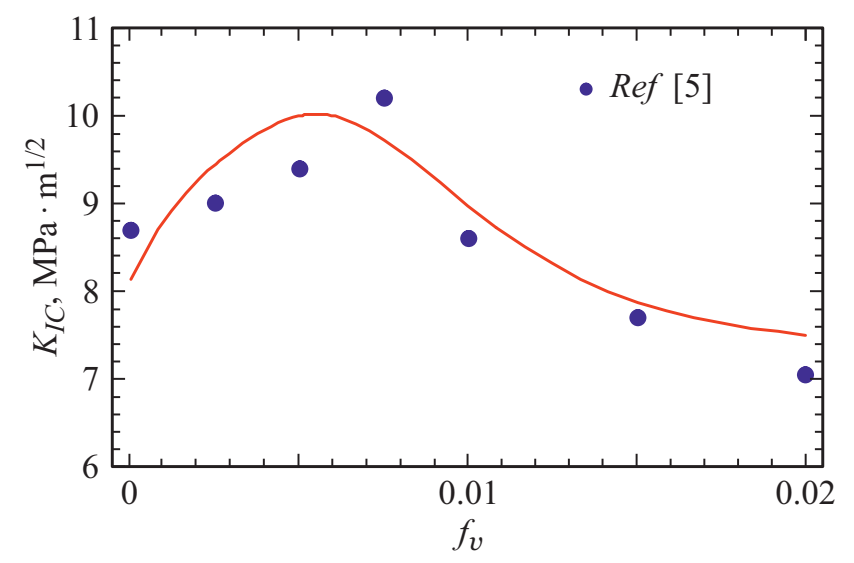

Рис. 3. Вязкость разрушения $K_{I C}$ композита $\mathrm{Al}_{2} \mathrm{O}_{3}-\mathrm{WC}-\mathrm{TiC}-G r$ как функция объемной доли $f_{v}$ графена. Для сравнения точками показаны экспериментальные значения вязкости разрушения [5]. 
агломерации $r^{*}$. Проведенное исследование позволяет заключить, что радиус агломерации $r^{*}$, зависящий от условий получения композитов, является важнейшим параметром, определяющим механические свойства керамических композитов с графеном.

\section{Финансирование работы}

Исследования выполнены при финансовой поддержке Минобрнауки России в рамках реализации программы Научного центра мирового уровня по направлению „Передовые цифровые технологии“ СПбПУ (соглашение № 075-15-2020-934 от 17.11.2020 г.).

\section{Конфликт интересов}

Авторы заявляют, что у них нет конфликта интересов.

\section{Список литературы}

[1] K. Markadan, J.K. Chin, J. Mater. Res., 32, 84 (2017). DOI: $10.1557 / \mathrm{jmr} .2016 .390$

[2] A. Nieto, A. Bisht, D. Lahiri, C. Zhang, A. Agarwal, Int. Mater. Rev., 62, 241 (2017). DOI: 10.1080/09506608.2016.1219481

[3] K.I. Vishnu Vandana, K.N.S. Suman, Int. J. Eng. Adv. Technol., 9, 5250 (2019). DOI: 10.35940/ijeat.B2873.129219

[4] Y. Liu, X. Jiang, J. Shi, Y. Luo, Y. Tang, Q. Wu, Z. Luo, Nanotechnol. Rev., 9, 190 (2020). DOI: $10.1515 /$ ntrev-2020-0017

[5] X. Wang, J. Zhao, E. Cui, S. Song, H. Liu, W. Song, Ceram. Int., 45, 10321 (2019). DOI: 10.1016/j.ceramint.2019.02.087

[6] H. Porwal, S. Gresso, M.J. Reece, Adv. Appl. Ceram., 112, 443 (2013). DOI: 10.1179/174367613X13764308970581

[7] C. Ramirez, P. Miranzo, M. Belmonte, M.I. Osendi, P. Poza, S.M. Vega-Diaz, M. Terrones, J. Eur. Ceram. Soc., 34, 161 (2014). DOI: 10.1016/j.jeurceramsoc.2013.08.039

[8] P. Hidalgo-Manrique, X. Lei, R. Xu, M. Zhou, I.A. Kinloch, R.J. Young, J. Mater. Sci., 54, 12236 (2019). DOI: $10.1007 / \mathrm{s} 10853-019-03703-5$

[9] J. Luo, R. Stevens, Ceram. Int., 25, 281 (1999). DOI: $10.1016 / \mathrm{S} 0272-8842(98) 00037-6$

[10] F. Shackelford, Y.-H. Han, S. Kim, S.-H. Kwon, CRC materials science and engineering handbook (CRC Press, Boca Raton, 2015), p. 509. DOI: $10.1201 / \mathrm{b} 18971$

[11] S.V. Bobylev, A.G. Sheinerman, Rev. Adv. Mater. Sci., 57, 54 (2018). DOI: 10.1515/rams-2018-0047

[12] M. Liu, C. Chen, Int. J. Solids Struct., 63, 32 (2015). DOI: 10.1016/j.ijsolstr.2015.02.031 